\title{
Childhood maltreatment: experiences and perceptions among Chinese young people
}

Yanyan Ni Ph.D. ${ }^{a}$, Therese Hesketh Ph.D. ${ }^{\text {bc }}$

${ }^{a}$ Institute for Women's Health, University College London, London, UK.

${ }^{a}$ Institute for Global Health, University College London, London, UK.

${ }^{\mathrm{c} I n s t i t u t e}$ for Global Health, School of Public Health, Zhejiang University, China.

Corresponding Author: Therese Hesketh, Institute for Global Health, University College London, 30

Guilford Street, London WC1N 1EH, UK and Centre for Global Health, School of Medicine, Zhejiang University, 866 Yuhangtang Lu, Hangzhou, China. Email: t.hesketh@ucl.ac.uk

Acknowledgements: We would like to thank all the college students who participated in the study and gave their time.

Funding: This work was supported by the China Scholar Council (CSC) and the Universities' China Committee in London (UCCL).

Conflicts of Interest: The authors have no conflicts of interest to disclose Authors' contributions: YN and TH had the original idea and designed the study. The research was supervised by TH. YN collected the data, conducted the statistical analysis and wrote the first draft of the manuscript. TH revised the manuscript. All authors have read and approved the final version of the manuscript. 
Childhood maltreatment: experiences and perceptions among Chinese young people

\section{Abstract}

The study aimed to investigate Chinese young people's childhood and adolescence exposure to maltreatment from all types of perpetrators, and to explore their perceptions of such experiences. A cross-sectional study was carried-out among 1255 young people at three universities located in Zhejiang Province, Eastern China. A questionnaire drawing on validated tools was developed to measure childhood and adolescence exposure to physical and emotional maltreatment. Physical and emotional maltreatment by any perpetrator before the age of 18 was reported by $83.3 \%$ and $85.9 \%$ of the students respectively; extreme forms were not rare. $68.8 \%$ of the students reported physical maltreatment by parents, $56.1 \%$ by teachers, $29.8 \%$ by peers, $11.7 \%$ by siblings, and $9.1 \%$ by grandparents; $58.5 \%$ reported emotional maltreatment by parents, $43.3 \%$ by teachers, $53.3 \%$ by peers, $12.0 \%$ by siblings, and $10.0 \%$ by grandparents. Physical or emotional maltreatment by any perpetrator was common in all socio-demographic groups, irrespective of urban/rural residence and economic status. Risk factors for maltreatment differ with type of maltreatment and perpetrator. Personal experience of emotional maltreatment was generally perceived as more harmful and less acceptable than physical, especially in females. In conclusion, high levels of maltreatment of children and adolescents in China indicate the need for 1) parent education about appropriate discipline measures when raising children; 2) teacher education and enforcement of existing laws banning institutional corporal punishment; 3) the adoption of a comprehensive anti-bullying strategy; 4) the development of a formal child protection system to protect and support the most vulnerable families.

Keywords Child Abuse; Bullying; Child abusers; Cultural Contexts; Perceptions of domestic violence 
Childhood maltreatment: experiences and perceptions among Chinese young people

\section{Introduction}

Child maltreatment is recognized as a major public health and social problem, with potentially devastating effects on children and families, as well as serious economic and social costs (Gilbert

et al., 2009). The launch of the Sustainable Developmental Goals (SDGs), calls for the ending of all forms of violence against children ("Transforming Our World: The 2030 Agenda for Sustainable Development," 2016), and has highlighted the global importance of this issue. Despite impressive progress in many areas of child health in China over recent decades, child protection remains a low priority. Child maltreatment is known to be common. It is often used as a form of discipline, and it is therefore widely regarded as a private matter for parents and carers. Over the last decade, a series of high-profile serious child maltreatment cases, has raised awareness of the seriousness of the problem of domestic child maltreatment. The Domestic Violence Act was enforced in March 2016. For the first time it is acknowledged that children need to be protected from violence in their own homes (The National People's Congress of the People's Republic of China, 2015). Importantly, the Act advocates a reporting system for suspected child abuse for the first time. This applies to medical professionals, teachers and childcare providers, who now have an obligation to report cases of abuse. However, how this will be implemented is unclear.

Most research on child maltreatment has taken place in western countries. Chinese researchers have only relatively recently started to take an interest in this area (Ji \& Finkelhor, 2015). A key barrier is that there is disagreement among Chinese researchers about how violence against children should be conceptualized. Considerable heterogeneity in definitions of child maltreatment creates problems in interpreting research findings. Physical punishment is still widely considered a legitimate means of disciplining children in the Chinese context, posing a 
Childhood maltreatment: experiences and perceptions among Chinese young people

major barrier to the development of effective prevention and intervention strategies for child protection in China.

Acquiring valid and reliable data about child maltreatment is a challenge. Prevalence rates reported by the Chinese studies are $7.6 \%-77.7 \%$ for physical maltreatment and $11.0 \%-79.5 \%$ for emotional maltreatment (Gao, Atkinson-Sheppard, \& Liu, 2017; Wang et al., 2016; Xiao \& Chen, 2011; Xu et al., 2008). Wide discrepancies exist in prevalence rates for a number of reasons, including variations in underlying definitions and perceptions, measurements, information sources, time periods, and research locations (Ji \& Finkelhor, 2015; Ni, 2018). Evidence now suggests that young adults are the most reliable respondents in terms of child maltreatment, because their recollections are relatively recent and they tend to be more willing to participate in research of this type (Finkelhor, Hotaling, \& Yllö, 1988). In addition, they will form the next generation of parents, and it is important to understand their experiences and perceptions of child punishment and maltreatment, in order to provide insight into how they may choose to discipline their own children.

Child maltreatment arises from three main sources: the intra-familial setting, from teachers at school, and from peers. Most studies, and especially those from China, focus on one particular source of violence, and one type of perpetrator, usually parents, whereas violence can of course be at the hands of different perpetrators. For example, massive rural-urban migration has resulted in tens of millions of Chinese children being left behind in rural areas, usually in the care of grandparents who take-on the traditional parental role of imposing discipline (Luo et al., 2008). Despite an increasing quantity of literature on this topic in China, there have been no studies extensively investigating maltreatment from different perpetrators. Additionally, there has been limited research in China to explore perceptions of various types of child maltreatment (Zhu 
Childhood maltreatment: experiences and perceptions among Chinese young people

\&Tang, 2011). Our study aimed first, to investigate the prevalence and risk factors of retrospective childhood and adolescent exposure to maltreatment in Chinese young people, and second, to explore perceptions of such experience, as well as the potential for harm. We specifically included different types of maltreatment and different perpetrators in order to gain an overview of child maltreatment experience. We excluded sexual abuse, since this is qualitatively different, and not on the punishment or discipline spectrum. The overall aim was to help to inform child protection measures in China.

\section{Methods}

\section{Participants}

A questionnaire survey was conducted among young people from January to May 2015 in Hangzhou, the capital of Zhejiang Province. This province has a population of 58 million and is one of the most developed in China. Hangzhou has a large student population and attracts students from all parts of the country. Young adults were recruited at three higher education institutions in Hangzhou using convenience sampling. Zhejiang University, Zhejiang Chinese Medical University and Hangzhou Medical College were purposively selected for inclusion in the study with the aim of representing high, middle and low level educational establishments and are ranked $4^{\text {th }}, 299^{\text {th }}$ and $706^{\text {th }}$ among all Chinese universities. The numbers of students are $54,641,14,282$, and 5,400 respectively. Permission was obtained from the senior management at all three institutions to conduct the research. The sample size was calculated using a prevalence rate of $36.6 \%$ for any child physical abuse prior to age 18 in China reported by a meta-analysis (Ji \& Finkelhor, 2015), with a precision of 5\% and a type 1 error of 5\%. Based on sample size calculation for cross sectional studies, at least 357 university students were needed. The study aimed for a sample size of 400 in each university. A total of 1,255 questionnaires were collected: 
Childhood maltreatment: experiences and perceptions among Chinese young people

396 from the high level establishment, 392 from middle level, and 467 from low level. Recruited participants broadly represented the student body across various disciplines. We aimed to sample undergraduates, but a very small number of postgraduates were also included.

\section{Procedure}

All questionnaires were completed in the classroom setting under 'exam conditions', given the sensitive nature of the topic. With the approval of the university teachers, a specific time was setaside in class for students to complete the questionnaires. We explained the purpose of the study to all participants. They were told they could refuse to participate and that they could stop at any time if they wanted. All participants gave consent, which appeared as the first page of the questionnaire. Strict anonymity and confidentiality were assured. After completion, questionnaires were placed directly into a collection box, which was then sealed. Afterwards, all respondents were given a helpline number of an advice service which specializes in adolescent mental health issues. The study was approved by the University College London Research Ethics Committee and Zhejiang University Ethics Board.

\section{Measurement}

The final version of the questionnaire had three main sections:

(1) Socio-demographic information: including sex, the number of children in the household, residence for the majority of their childhood (urban or rural), parents' marital status (married, separated/divorced, widowed, remarried), maternal and paternal education (university or above, high school, middle school, primary school or below), perceived household economic status in comparison with the local community (high, middle, low), and residence status (living with both parents, living with either parent, living with neither). 
Childhood maltreatment: experiences and perceptions among Chinese young people

(2) Experience of maltreatment: a) seven items of physical maltreatment, including hitting, punching, kicking, shaking, stabbing/cutting with a knife or sharp object, burning or scalding, and non-contact punishment (e.g., forcing to kneel or stand as a punishment); b) seven items of emotional maltreatment, including insulting or criticizing that made them feel stupid or worthless, threatening to hit, and threatening with abandonment. Participants were asked about experiences under the age of 18 with three response options: 'yes', 'no', and 'cannot remember'. If they answered 'yes', they were asked who the perpetrator was with a choice of parents, teachers, peers, siblings or grandparents and the extent of the harm they felt as a result of the experience, classified as: 'very severe', 'severe', 'mild', and 'not at all'. A series of binary variables for physical and emotional maltreatment (yes vs no) were created depending on whether they had reported any form of physical or emotional maltreatment: maltreatment by any perpetrator, maltreatment by parents and maltreatment by non-parents.

(3) Perceptions of childhood experience: participants were asked two general questions about perceptions of experience of physical and emotional maltreatment, firstly, whether they felt it was justified, and secondly, how it compared with their peers experience.

The sections of experiences and perceptions in relation to maltreatment were developed by primarily drawing on the existing validated tool which has been extensively used in many countries: the International Society for the Prevention of Child Abuse and Neglect (ISPCAN) Child Abuse Screening Tool Retrospective version (ICAST-R) (Dunne et al., 2009). ICAST-R was developed by experts from 28 countries and has satisfactory properties for adoption as a survey tool to collect data from young people aged 18-24 on child maltreatment in different cultural settings (Dunne et al., 2009). It includes five questions for physical maltreatment and five for emotional, with follow-up questions about perpetrator characteristics. To our knowledge 
Childhood maltreatment: experiences and perceptions among Chinese young people

it has not been used previously in Mainland China. Two additional items were derived from the Conflict Tactics Scale-Parent Child (CTSPC) (Straus, Hamby, Finkelhor, Moore, \& Runyan, 1998), such as burning or scalding and threatening to spank without actually doing it. CTSPC was developed as an extension of the original Conflict Tactics Scales to measure parents' discipline in conflict situations (Straus, 1979). The Chinese version has shown good validity and reliability in Hong Kong (Chan, 2005), with Cronbach's alpha ranging from 0.77 to 0.88 (Chan et al., 2012). In addition, non-contact punishment was considered as 'physical maltreatment' in many Chinese studies (Xiao et al., 2008), such as standing/kneeling as a punishment, and thus it was also included in the questionnaire. The questionnaire underwent translation, back-translation and revisions, taking into consideration particular nuances of language. A pilot study was conducted among 65 college students, and the questionnaire was then amended slightly according to the students' feedback, to maximize its suitability for the Chinese setting. For instance, the item refusing to talk to them/ignoring that made them feel hurt was added. Cronbach's alpha in our sample was 0.72 .

\section{Analysis}

Odds ratios (ORs) and their 95\% confidence intervals (CIs) were estimated using binary logistic regression models to examine risk factors of physical and emotional maltreatment, including child sex, the number of children, residence, parents' marital status, parents' education, economic status and residence status in childhood. Student reporting 'cannot remember' were excluded when calculating the prevalence rates and analyzing risk factors. We then focused on students in the maltreatment group and analyzed their perceptions of harm. SPSS 23.0 was used for data analysis.

\section{Results}


Childhood maltreatment: experiences and perceptions among Chinese young people

Among 1255 questionnaires collected, 1201 were analyzed, after excluding 54 because of missing key variables (Table 1); 52\% of the respondents were female; $382(31.8 \%)$ were from the high level educational establishment, 366 (30.4\%) the middle level, and $453(37.7 \%)$ from the low level. Participants were aged 17-26 years (mean 19.7); 59.2\% were resident in rural areas; $48.7 \%$ were only children.

\section{Prevalence of Maltreatment}

Overall, $94.4 \%$ of the students reported having experienced some form of violence by any perpetrator before the age of 18: $83.3 \%$ for physical and $85.9 \%$ for emotional (Table 2). Prevalence of different forms of childhood maltreatment were presented in Table 3. Males were more likely than females to report physical maltreatment by any perpetrator $(86.9 \%$ vs $79.9 \%, \mathrm{OR}[95 \% \mathrm{CI}]=$ $1.83[1.32,2.55], P<0.001$; Table 4); being an only child was a protective factor $(81.0 \%$ vs $85.6 \%$, $\mathrm{OR}=0.69[0.48,0.99], P=0.043)$. Sex and being an only child was not significantly associated with emotional maltreatment by any perpetrator. Other socio-demographic variables, including urban/rural residence, parents' marital status and education level, and household economic status, were not risk factors for physical or emotional maltreatment by any perpetrator.

Maltreatment by parents was reported by $83.2 \%$ of students: $68.8 \%$ for physical and $58.5 \%$ for emotional. Physical maltreatment by teachers, peers, siblings and grandparents was reported as $56.1 \%, 29.8 \%, 11.7 \%$ and $9.1 \%$ respectively, while emotional maltreatment by teachers, peers, siblings and grandparents was reported by $43.3 \%, 53.3 \%, 12.0 \%$ and $10.0 \%$.

\section{Risk Factors for Maltreatment}

Sex was significantly associated with both physical and emotional maltreatment by parents (Table 4): males reported significantly more physical maltreatment than females $(71.6 \%$ vs $66.1 \%$, $\mathrm{OR}=1.33[1.02,1.73], P=0.037)$ but less emotional maltreatment $(54.0 \%$ vs $62.9 \%, \mathrm{OR}=0.71[0.54$, 
Childhood maltreatment: experiences and perceptions among Chinese young people

0.91], $P=0.008)$. No other factors were significantly associated with physical maltreatment by parents. However, urban residence was significantly associated with less emotional maltreatment by parents $(55.0 \%$ vs $63.7 \%$, OR=0.63[0.47, 0.86], $P=0.004)$.

Risk factors of maltreatment differed with type of perpetrator (see Table 4). Males reported more physical maltreatment by teachers $(\mathrm{OR}=2.07[1.60,2.69], P<0.001)$ and peers $(\mathrm{OR}=2.09[1.52$, 2.82], $P<0.001)$. Living with both parents was a protective factor for maltreatment by teachers (physical $\mathrm{OR}=0.54[0.32,0.92], \quad P=0.024$; emotional $\mathrm{OR}=0.57[0.35,0.92], P=0.023$ ) and grandparents (physical OR=0.23[0.12, 0.45], $P<0.001$; emotional $\mathrm{OR}=0.25[0.12,0.50], P<0.001$ ). Father's lower educational backgrounds was a risk factor for physical maltreatment by peers (high school vs primary school or below: $\mathrm{OR}=0.60[0.38,0.94], P=0.026$; high school vs middle school: $\mathrm{OR}=0.56[0.38,0.83], P=0.003)$. Low-income economic status was positively associated with physical maltreatment by grandparents $(\mathrm{OR}=3.00[1.32,6.79], P=0.008)$.

\section{Common Forms}

The most common reported forms of maltreatment by parents were hitting/punching (53.6\%), hitting with implements (29.4\%), threatening to hit (29.5\%), insulting or criticizing that made them feel stupid or worthless (22.1\%), and forcing to stand/kneel in a humiliating or painful way (18.5\%). Most common forms of violence by teachers were forcing to stand/kneel (37.6\%), insults (32.7\%), hitting/punching (20.9\%) and hitting with implements (10.4\%). By peers most common forms were ignoring/refusing to talk (29.3\%), threatening to hit (17.2\%), and kicking (12.9\%). By siblings common forms were hitting/punching (5.2\%), ignoring/refusing to talk (4.8\%), and kicking (3.1\%). Common forms by grandparents were hitting/punching (5.2\%) and threatening to hit (4.4\%). Extreme forms of maltreatment occurred: stabbing/cutting with a knife/sharp object $(2.1 \%)$ and burning/scalding/puncturing (1.3\%), mainly perpetrated by parents or peers. 
Childhood maltreatment: experiences and perceptions among Chinese young people

\section{Perceptions of personal experience}

Of the 969 young people who experienced physical maltreatment, 734(75.7\%) regarded it as reasonable and justified discipline. Over half (52.7\%) thought they experienced less physical punishment than their peers, while 365 (37.8\%) thought it was about the same. Of 980 students who experienced emotional maltreatment, 406(41.4\%) thought it reasonable and justified. Again a majority, $592(61.0 \%)$ felt they experienced less than peers, and 321(33.1\%) considered their experience was about the same as other children.

\section{Perceptions of harm}

Hitting/punching, the use of implements, kicking and being forced to stand/kneel were reported to cause severe or very severe harm (Table 5; proportion range 9.7\%-15.0\%). Perpetrators were mainly parents or teachers (Figure 1). Extreme forms such as burning/scalding/puncturing and stabbing/cutting with a knife or sharp object, were perceived as harmful by the overwhelming majority. Emotional maltreatment, mainly perpetrated by parents or teachers was perceived to be more harmful overall, with more respondents reporting severe or very severe harm caused by such experience (proportion range $24.1 \%-44.4 \%$ ). Being ignored and being physically threatened, both mainly perpetrated by peers, were also perceived as harmful by the majority (proportion range 18.8\%-22.2\%).

\section{Discussion}

This is the first study to consider all types of perpetrators in China. Despite an increasing amount of literature on this topic in China, most studies only focus on one particular source of violence (e.g., parents), and fail to distinguish maltreatment by perpetrator (Chen et al., 2017). Our study raises a number of important issues. First, we show very high levels of childhood and adolescent exposure to maltreatment, as reported retrospectively by young people. As previously noted it is 
Childhood maltreatment: experiences and perceptions among Chinese young people

widely thought that young adults are the most reliable respondents in relation to child maltreatment, not only because their recollections are relatively recent, but they can also contextualize and reflect on the experience (Finkelhor et al., 1988). Extreme forms such as stabbing/cutting with a knife or sharp object were not rare. Secondly, physical or emotional maltreatment by any perpetrator was common in all socio-demographic groups, irrespective of urban/rural residence and economic status. More importantly, however, our study shows that risk factors for maltreatment differ with type of maltreatment and perpetrator. Thirdly, many students felt harmed by their experience, and experience of emotional maltreatment was more harmful and less acceptable than physical.

High rates of childhood maltreatment perpetrated by parents across all socio-demographic groups indicate the virtual normalization of child maltreatment in China with physical punishment and verbal aggression accepted as forms of discipline for raising children (Chao \& Sue, 1996; Ni, Zhou, Li, \& Hesketh, 2018). This contrasts with many other settings where factors such as poverty and low educational level, are strongly associated with child maltreatment (Gilbert et al., 2009). Our numbers are higher than estimates from many other countries (Hillis, Mercy, Amobi, \& Kress, 2016; Stoltenborgh, Bakermans-Kranenburg, Alink, \& van IJzendoorn, 2015), but fall into the upper range of the rates reported by other Chinese studies: $7.6 \%-77.7 \%$ for physical maltreatment and $11.0 \%-79.5 \%$ for emotional (Gao, AtkinsonSheppard, \& Liu, 2017; Wang et al., 2016; Xiao \& Chen, 2011; Xu et al., 2008). Consistent with most studies(Wang \& Chen, 2012), males reported significantly more physical maltreatment by parents. Evidence of sex differences for emotional maltreatment by parents is mixed with many reporting no difference (Wong et al., 2009). It was reported more by females in our study, in line with three other Chinese studies (Chan, Emery, \& Ip, 2016; Lin et al., 2011; Wan, Chen, Sun, \& 
Childhood maltreatment: experiences and perceptions among Chinese young people

Tao, 2015). It has been suggested that females may be more vulnerable to parental criticism and hostility, which could lead to recall bias, and hence higher rates of reporting (McGee, Wolfe, \& Wilson, 1997). Rural residence was a risk factor for emotional (but not physical) maltreatment by parents in this study. This could be explained by high levels of stress and low social support, associated with poverty and low quality caregiving environments (Berger, 2004). Inconsistency with previous studies in relation to prevalence rates and risk factors is possibly for a number of reasons, including variations in underlying definitions and perceptions, measurements of risk factors and outcomes and information sources (Ji \& Finkelhor, 2015; Ni, 2018).

We confirm that corporal punishment was still widely used by teachers in schools, and was reported more by boys, despite it being officially banned by law over 30 years ago (China Ministry of Education, 1986). The high rate of corporal punishment was reported in another study: $51.1 \%$ (minor $28.0 \%$; serious $4.1 \%$ ) (Kim et al., 2000). A number of reports of severe maltreatment in primary schools and kindergartens have been reported recently in Chinese media (China Daily, 2017; Xinhuanet, 2017), raising awareness of institutional abuse even for young children. High rates in this study may also partly reflect the social and cultural acceptance that physical punishment may actually improve children's academic performance. However, evidence from elsewhere suggests there is a link between physical punishment in schools and adverse outcomes in children/adolescents in terms of poor academic performance and poorer psychosocial well-being (Jones \& Pells, 2016).

We show that many (30\%) had experienced physical violence by peers with males more affected, in line with previous research (Cheng et al., 2010); emotional maltreatment by peers is even more common (53\%). Our findings suggest that peer maltreatment, or bullying, can have longterm adverse effects on the psychological well-being of adolescents, and more so than children 
Childhood maltreatment: experiences and perceptions among Chinese young people

mistreated by parents or caregivers. Similar results have come from longitudinal studies in many countries (Lereya, Copeland, Costello, \& Wolke, 2015). There has been a growing interest in bullying among Chinese researchers since the 1990s. However, they have primarily focused on short-term effects and most were cross-sectional studies (Cheng et al., 2010). Extreme cases reported by the internet and social media in the recent years have attracted lots of attention from the public. The authorities have pledged to fight against school bullying and have released several anti-bullying policies, for instance, Strengthen the Comprehensive Management Plan for Bullying in Primary and Middle School Students (China Ministry of Education, 2017). However, it is unclear these will be implemented and whether they will be effective.

Importantly, this study raises concerns about maltreatment by grandparents, which is not rare, but often ignored in research. Not surprisingly, low economic status and not living with both parents in childhood were found to be risk factors for maltreatment by grandparents. Research in the field of kinship care in western countries has proposed explanations of increased levels of psychological stress, inadequate financial resources, and the physical demands of parenting later in life (Harnett, Dawe, \& Russell, 2014; Kelley, Whitley, \& Campos, 2011) and these factors may be important in the Chinese setting.

Our study indicated a remarkably high acceptance of physical maltreatment, with the majority perceiving it as reasonable and justified. Similar findings came from a qualitative study from China, which found that children think it is reasonable for parents to punish them physically, if they behave badly, and even that is an expression of parental love (Zhu \& Tang, 2011). Our findings also indicated that there was a perceived 'normalization' of physical and emotional maltreatment of children in China. Previous studies have shown that such perception might moderate negative effects of maltreatment on children (Lansford et al., 2005). However, 
Childhood maltreatment: experiences and perceptions among Chinese young people

evidence from this study certainly showed that many students felt harmed by their experience of maltreatment. This is consistent with research from Western countries and from China, which showed long-term negative effects of maltreatment on the mental health and well-being of children (Gilbert et al., 2009; McGee et al., 1997; Wang, Wang, \& Liu, 2016). Our finding that experience of emotional maltreatment was more harmful and less acceptable than physical, has been observed elsewhere (McGee et al., 1997; Wang et al., 2016). However, this issue has generally received less attention than other forms of maltreatment, even in high-income countries (Gilbert et al., 2009). Given the high prevalence of emotional maltreatment in China, the longterm effects need to be explored further.

\section{Limitations}

The study has a number of limitations. First, this is clearly a highly sensitive topic which may cause discomfort to participants, as they were asked to report possible unpleasant and painful experiences in childhood. Secondly, the sample comprised students attending universities in one city. While our sampling aimed to ensure diversity of the participants across socio-economic status and sex within the target population, the findings clearly cannot be generalized and are not applicable to all in the population. Thirdly, while young adults are regarded as the most reliable respondents for research of this type, there is potential for underestimates, given the fact that many students reported that they did not have clear recollection about punishments. Participants being the source of information for both the independent and dependent variables also raises the problem of shared source variance, which may introduce systematic biases in estimates of associations among variables. Fourthly, the study asked participants about their perceptions of harm caused by different acts, with no specific definition of harm provided, so interpretations are likely to have varied. It was also not clear whether participants reported short-term or longstanding harm. 
Childhood maltreatment: experiences and perceptions among Chinese young people

Qualitative research should be conducted in future to contribute to a better understanding of perceived harm. In addition, the extent of the harm participants felt from the maltreatment experience was measured with a subjective scale of 'very severe', 'severe', 'mild', and 'not at all'. We have to be cautious in interpreting our findings due to the subjective assessment of harm and the retrospective assessment of childhood experience. There is potential for bias when participants effort to link their experience with later harm. Lastly, due to the properties of cross-sectional studies, the relationship between each risk factor and maltreatment could only be correlative. The ability to establish the causal relationship is restricted. Moreover, risk factors in this study are essentially demographic factors. Future research should adopt a qualitative approach to disentangle a broad range of individual, psychological, family dynamics that may be relevant as risk factors.

\section{Implications for policy}

The policy implications of the study have been considerably influenced by the introduction of the Domestic Violence Act. The idea of reporting child abuse advocated by the new Act is still contrary to culturally-justified tolerance toward corporal punishment and the belief that child discipline is a family matter, which is illustrated in our study. It is likely to be a long time before such a reporting mechanism is widely accepted (Zhao, Hamalainen, \& Chen, 2017).

Against the background of this change in the Law, our findings have further implications. First, there is a need to raise awareness about the negative effects of child maltreatment, which will help to justify the need for the new Law in a possibly sceptical population. The focus should be on national campaigns, especially using social media platforms, which are widely used in China. There has been limited publicity about this law and anecdotally it seems that few people are aware of it, so this must be addressed. Along with increasing awareness of the dangers of maltreatment for children, parents and grandparents need to learn how to discipline children in a 
Childhood maltreatment: experiences and perceptions among Chinese young people

constructive and non-punitive way. Specific parenting education programs could be provided in health settings or immunization clinics with monitoring and evaluation to determine effectiveness.

Secondly, now that teachers have been given the task of reporting on domestic abuse, the fact that corporal punishment in schools is common is somewhat ironic. The existing law needs to be strictly enforced. Teachers need to be trained and supported in management techniques that focus on finding constructive solutions to challenging situations.

Thirdly, anti-bullying programs should be developed to prevent and protect children from peer maltreatment. There are existing models for this. The effectiveness of the whole-school intervention approach in preventing and reducing traditional school bullying has been proven in western countries and Hong Kong (Olweus, 1994; Wong, 2004). Examples of key elements include creating a positive school climate and enforcing a clear and strong anti-bullying policy, training of teachers and parents in handling school bullying, and assisting students to develop adequate self-competency and strong social skills.

The Domestic Violence Act represents real progress, in terms of a starting point for a child protection framework. In terms of implementation, however, there are challenges. First, currently no single agency takes formal responsibility for child protection and there are no placement services for severely maltreated children (Man, Barth, Li, \& Wang, 2017). Second, procedures and standards for evaluating cases of child abuse and neglect need to be developed. This all requires training of a cohort of child protection specialists. There is a key role for the new and growing discipline of social work, and for partnerships with civil society(Chui \& Jordan, 2018). 
Childhood maltreatment: experiences and perceptions among Chinese young people

\section{References}

Appel, A.E., Holden, G.W. (1998). The co-occurrence of spouse and physical child abuse: A review and appraisal. Journal of Family Psychology, 12(4), 578-599.

Berger, L. M. (2004). Income, family structure, and child maltreatment risk. Children and Youth Services Review, 26(8), 725-748. doi:10.1016/j.childyouth.2004.02.017

Chan, E. K. L. (2005). Study on Child abuse and Spouse Battering: Report on Findings of Household Survey (A Consultancy Study Commissioned by the SWD of the HKSAR). Hong Kong: Deprtment of Social Work \& Social Administration, the University of Hong Kong.

Chan, K. L., Brownridge, D. A., Fong, D. Y., Tiwari, A., Leung, W. C., \& Ho, P. C. (2012). Violence against pregnant women can increase the risk of child abuse: A longitudinal study. Child Abuse \& Neglect, 36(4), 275-284.

Chan, K. L., Emery, C. R., \& Ip, P. (2016). Children With Disability Are More at Risk of Violence Victimization: Evidence From a Study of School-Aged Chinese Children. $J$ Interpers Violence, 31(6), 1026-1046. doi:10.1177/0886260514564066

Chao, R. K., \& Sue, S. (1996). Chinese parental influence and their children's school success: A paradox in the literature on parenting styles. Growing up the Chinese way: Chinese child and adolescent development, 93-120.

Chen, Y. L., Liu, X., Huang, Y., Yu, H. J., Yuan, S., Ye, Y. L., . . He, Q. Q. (2017). Association between Child Abuse and Health Risk Behaviors among Chinese College Students. Journal of Child and Family Studies, 26(5), 1380-1387. doi:10.1007/s10826-017-0659-y

Cheng, Y. L., Newman, I. M., Qu, M., Mbulo, L., Chai, Y., Chen, Y., \& Shell, D. F. (2010). Being Bullied and Psychosocial Adjustment Among Middle School Students in China. Journal of School Health, 80(4), 193-199.

China Daily. (2017). Female teacher of RYB kindergarten held for 'child abuse'. Retrieved from http://www.chinadaily.com.cn/china/2017-11/25/content_34987525.htm

Chui, C. H. K., \& Jordan, L. (2018). Child protection in China: threats and opportunities. Asia Pacific Journal of Social Work and Development, 28(2), 84-96. doi:10.1080/02185385.2018.1432411

Dunne, M. P., Zolotor, A. J., Runyan, D. K., Andreva-Miller, I., Choo, W. Y., Dunne, S. K., ... Kasim, M. S. (2009). ISPCAN Child Abuse Screening Tools Retrospective version 
Childhood maltreatment: experiences and perceptions among Chinese young people

(ICAST-R): Delphi study and field testing in seven countries. Child Abuse \& Neglect, $33(11), 815-825$.

Finkelhor, D., Hotaling, G. T., \& Yllö, K. (1988). Stopping family violence: Research priorities for the coming decade: Sage Publications, Inc.

Gao, Y., Atkinson-Sheppard, S., \& Liu, X. (2017). Prevalence and risk factors of child maltreatment among migrant families in China. Child Abuse Negl, 65, 171-181. doi:10.1016/j.chiabu.2017.01.023

Gilbert, R., Widom, C. S., Browne, K., Fergusson, D., Webb, E., \& Janson, S. (2009). Burden and consequences of child maltreatment in high-income countries. Lancet, 373(9657), 68-81. doi:10.1016/S0140-6736(08)61706-7

Harnett, P. H., Dawe, S., \& Russell, M. (2014). An investigation of the needs of grandparents who are raising grandchildren. Child \& Family Social Work, 19(4), 411-420. doi:10.1111/cfs.12036

Hillis, S., Mercy, J., Amobi, A., \& Kress, H. (2016). Global Prevalence of Past-year Violence Against Children: A Systematic Review and Minimum Estimates. Pediatrics, 137(3). doi:ARTN e2015407910.1542/peds.2015-4079

Ji, K., \& Finkelhor, D. (2015). A meta-analysis of child physical abuse prevalence in China. Child Abuse Negl, 43, 61-72. doi:10.1016/j.chiabu.2014.11.011

Jones, H., \& Pells, K. (2016). Undermining Learning: Multi-Country Longitudinal Evidence on Corporal Punishment in Schools. UNICEF. Office of Research-Innocenti. Retrieved from http://disde.minedu.gob.pe/handle/123456789/4063

Kelley, S. J., Whitley, D. M., \& Campos, P. E. (2011). Behavior problems in children raised by grandmothers: The role of caregiver distress, family resources, and the home environment. Children and Youth Services Review, 33(11), 2138-2145. doi:10.1016/j.childyouth.2011.06.021

Kim, D. H., Kim, K. I., Park, Y. C., Zhang, L. D., Lu, M. K., \& Li, D. G. (2000). Children's experience of violence in China and Korea: A transcultural study. Child Abuse \& Neglect, 24(9), 1163-1173. doi:Doi 10.1016/S0145-2134(00)00175-7

Lansford, J. E., Chang, L., Dodge, K. A., Malone, P. S., Oburu, P., Palmerus, K., . . Quinn, N. (2005). Physical discipline and children's adjustment: Cultural normativeness as a 
Childhood maltreatment: experiences and perceptions among Chinese young people

moderator. Child Development, 76(6), 1234-1246. doi:10.1111/j.1467-

8624.2005.00847.x

Lereya, S. T., Copeland, W. E., Costello, E. J., \& Wolke, D. (2015). Adult mental health consequences of peer bullying and maltreatment in childhood: two cohorts in two countries. Lancet Psychiatry, 2(6), 524-531. doi:10.1016/S2215-0366(15)00165-0

Lin, R. S., Liu, W. J., Zhang, W. W., Liu, W., Lin, L., Wu, J. G., \& Du, L. (2011). Situation and influencing factors of abuse among children in Guangzhou. Chinese Journal of Child Health Care, 19(01), 21-23.

Luo, J. Y., Peng, X. C., Zong, R., Yao, K. B., Hu, R. S., Du, Q. Y., . . Zhu, M. Y. (2008). The status of care and nutrition of 774 left-behind children in rural areas in China. Public Health Reports, 123(3), 382-389.

Man, X. O., Barth, R. P., Li, Y. E., \& Wang, Z. B. (2017). Exploring the new child protection system in Mainland China: How does it work? Children and Youth Services Review, 76, 196-202. doi:10.1016/j.childyouth.2017.03.012

McGee, R. A., Wolfe, D. A., \& Wilson, S. K. (1997). Multiple maltreatment experiences and adolescent behavior problems: Adolescents' perspectives. Dev Psychopathol, 9(1), 131149.

Ni, Y. (2018). Child discipline and maltreatment in Zhejiang Province of China: perceptions, risk factors, experiences and impacts (Doctoral dissertation, UCL (University College London)).

Ni, Y., Zhou, X., Li, L., \& Hesketh, T. (2018). Child Maltreatment in the Zhejiang Province of China: The Role of Parental Aggressive Tendency and a History of Maltreatment in Childhood. Child Abuse Review, 27(5), 389-403. doi:10.1002/car.2520

Olweus, D. (1994). Annotation - Bullying at School - Basic Facts and Effects of a School-Based Intervention Program. Journal of Child Psychology and Psychiatry and Allied Disciplines, 35(7), 1171-1190. doi:DOI 10.1111/j.1469-7610.1994.tb01229.x

Stoltenborgh, M., Bakermans-Kranenburg, M. J., Alink, L. R. A., \& van IJzendoorn, M. H. (2015). The Prevalence of Child Maltreatment across the Globe: Review of a Series of Meta-Analyses. Child Abuse Review, 24(1), 37-50. doi:10.1002/car.2353

Straus, M. A. (1979). Measuring intrafamily conflict and violence: The conflict tactics (CT) scales. Journal of Marriage and the Family, 75-88. 
Childhood maltreatment: experiences and perceptions among Chinese young people

Straus, M. A., Hamby, S. L., Finkelhor, D., Moore, D. W., \& Runyan, D. (1998). Identification of child maltreatment with the Parent-Child Conflict Tactics Scales: development and psychometric data for a national sample of American parents. Child Abuse Negl, 22(4), 249-270.

The National People's Congress of the People's Republic of China. (2015). The Anti-domestic Violence Law of the People's Republic of China. Retrieved from http://www.npc.gov.cn/npc/xinwen/2015-12/28/content_1957457.htm

Transforming Our World: The 2030 Agenda for Sustainable Development. (2016). Ocean Yearbook, 30(1), 782-824. doi:10.1163/9789004321595_029

Wan, Y. H., Chen, J., Sun, Y., \& Tao, F. B. (2015). Impact of Childhood Abuse on the Risk of Non-Suicidal Self-Injury in Mainland Chinese Adolescents. PLoS One, 10(6). doi:10.1371/journal.pone.0131239

Wang, G. F., Jiang, L., Wang, L. H., Hu, G. Y., Fang, Y., Yuan, S. S., . . Su, P. Y. (2016). Examining Childhood Maltreatment and School Bullying Among Adolescents: A CrossSectional Study From Anhui Province in China. J Interpers Violence. doi:10.1177/0886260516647000

Wang, M. F., Wang, X. X., \& Liu, L. (2016). Paternal and maternal psychological and physical aggression and children's anxiety in China. Child Abuse \& Neglect, 51, 12-20. doi:10.1016/j.chiabu.2015.11.018

Wang, Y. H., \& Chen, J. Q. (2012). Analysis on chilhood abuse experience and the influencing factors among 1762 college students. Modern Preventive Medicine(18), 4654-4656.

Wong, D. S. (2004). School bullying and tackling strategies in Hong Kong. Int J Offender Ther Comp Criminol, 48(5), 537-553. doi:10.1177/0306624X04263887

Wong, W. C. W., Leung, P. W. S., Tang, C. S. K., Chen, W. Q., Lee, A., \& Ling, D. C. (2009). To unfold a hidden epidemic: Prevalence of child maltreatment and its health implications among high school students in Guangzhou, China. Child Abuse \& Neglect, 33(7), 441-450. doi:10.1016/j.chiabu.2008.02.010

Xiao, W. Q., \& Chen, J. Q. (2011). Physical violence against children, a survey in 560 kindergarten children's parents/guardians Chinese Journal of Child Health Care(03), 230-232. 
Childhood maltreatment: experiences and perceptions among Chinese young people

Xiao, Y.N., Tao, F.B., Xu, S.J., Su, P.Y., Huang, C.H. (2008). Self-injurious Behaviors in Adolescents with Repeated Childhood Abuse. Chinese Journal of Public Health, 24(09):1028-1030.

Xinhuanet. (2017). Day care center suspended over child abuse. Retrieved from http://www.chinadaily.com.cn/china/2017-11/09/content_34317858.htm

Xu, X. J., Chen, W. Q., Han, K., Wen, X. Z., Huang, Z. W., \& Li, D. B. (2008). Prevalence of Family Abuse Among Junior Middle School Students in Guangzhou. Chinese Journal of School Health, 29(06), 515-518.

Zhao, F., Hamalainen, J. E. A., \& Chen, H. L. L. (2017). Child protection in China: Changing policies and reactions from the field of social work. International Journal of Social Welfare, 26(4), 329-339. doi:10.1111/ijsw.12268

Zhu, Y. H., \& Tang, K. L. (2011). Physical child abuses in urban China: Victims' perceptions of the problem and impediments to help-seeking. International Social Work, 55(4), 574-588. doi:10.1177/0020872811425806 
Table 1. Socio-Demographic Profile of Participants $(\mathrm{N}=1201)$

\begin{tabular}{|c|c|c|}
\hline Variables & $n$ & $\%$ \\
\hline Age $(X \pm S)$ & $19.7 \pm 1.3$ & Range $17-26$ \\
\hline \multicolumn{3}{|l|}{ Gender } \\
\hline Male & 582 & 48.5 \\
\hline Female & 619 & 51.5 \\
\hline \multicolumn{3}{|l|}{ Single child } \\
\hline Yes & 585 & 48.7 \\
\hline No & 616 & 51.3 \\
\hline \multicolumn{3}{|l|}{ Residence } \\
\hline Urban & 490 & 40.8 \\
\hline Rural & 711 & 59.2 \\
\hline \multicolumn{3}{|l|}{ Parents' marital status } \\
\hline Married & 1109 & 92.3 \\
\hline Separated/ Divorced & 51 & 4.2 \\
\hline Widowed & 22 & 1.8 \\
\hline Remarried & 19 & 1.6 \\
\hline \multicolumn{3}{|l|}{ Mother's education } \\
\hline Primary school or below & 388 & 32.3 \\
\hline Middle school & 439 & 36.6 \\
\hline High school & 210 & 17.5 \\
\hline University or above & 164 & 13.7 \\
\hline \multicolumn{3}{|l|}{ Father's education } \\
\hline Primary school or below & 272 & 22.6 \\
\hline Middle school & 414 & 34.5 \\
\hline High school & 292 & 24.3 \\
\hline University or above & 223 & 18.6 \\
\hline \multicolumn{3}{|c|}{ Self-reported economic status } \\
\hline High-income & 163 & 13.6 \\
\hline Middle & 801 & 66.7 \\
\hline Low-income & 237 & 19.7 \\
\hline \multicolumn{3}{|l|}{ Residence status } \\
\hline Living with both parents & 1042 & 86.8 \\
\hline Only with mother & 55 & 4.6 \\
\hline Only with father & 12 & 1.0 \\
\hline Neither & 92 & 7.7 \\
\hline
\end{tabular}

Note: percentages do not all add up to $100 \%$ because of missing values. 
Table 2. Prevalence of Childhood Maltreatment by Sex and Perpetrator

\begin{tabular}{|c|c|c|c|c|}
\hline Childhood maltreatment & $\begin{array}{c}\text { Total } \\
n / \mathrm{N}(\%)\end{array}$ & $\begin{array}{c}\text { Male } \\
n / \mathrm{N}(\%)\end{array}$ & $\begin{array}{c}\text { Female } \\
n / \mathrm{N}(\%)\end{array}$ & $P$ \\
\hline Childhood maltreatment by any perpetrator & $1113 / 1179(94.4)$ & $549 / 573(95.8)$ & $564 / 606(93.1)$ & 0.041 \\
\hline Physical maltreatment by any perpetrator & $969 / 1163(83.3)$ & $491 / 565(86.9)$ & $478 / 598(79.9)$ & 0.001 \\
\hline Emotional maltreatment by any perpetrator & $980 / 1141(85.9)$ & $474 / 556(85.3)$ & $506 / 585(86.5)$ & 0.546 \\
\hline Childhood maltreatment by parents & $914 / 1099(83.2)$ & $447 / 533(83.9)$ & $467 / 566(82.5)$ & 0.548 \\
\hline Physical maltreatment by parents & $760 / 1105(68.8)$ & $385 / 538(71.6)$ & $375 / 567(66.1)$ & 0.052 \\
\hline Emotional maltreatment by parents & $610 / 1042(58.5)$ & $276 / 511(54.0)$ & $334 / 531(62.9)$ & 0.004 \\
\hline Childhood maltreatment by others & 994/ 1137( 87.4) & $501 / 554(90.4)$ & $493 / 583(84.6)$ & 0.003 \\
\hline Physical maltreatment by others & $757 / 1097(69.0)$ & $408 / 535(76.3)$ & $349 / 562(62.1)$ & $<0.001$ \\
\hline Teachers & $583 / 1039(56.1)$ & $326 / 509(64.0)$ & $257 / 530(48.5)$ & $<0.001$ \\
\hline Peers & $280 / 941(29.8)$ & $170 / 471(36.1)$ & $110 / 470(23.4)$ & $<0.001$ \\
\hline Siblings & $103 / 883(11.7)$ & $54 / 438(12.3)$ & $49 / 445(11.0)$ & 0.542 \\
\hline Grandparents & $80 / 878(9.1)$ & $39 / 432(9.0)$ & $41 / 446(9.2)$ & 0.932 \\
\hline Emotional maltreatment by others & $825 / 1103(74.8)$ & $406 / 544(74.6)$ & $419 / 559(75.0)$ & 0.902 \\
\hline Teachers & $431 / 995(43.3)$ & $216 / 500(43.2)$ & $215 / 495(43.4)$ & 0.941 \\
\hline Peers & $546 / 1024(53.3)$ & $280 / 516(54.3)$ & $266 / 508(52.4)$ & 0.542 \\
\hline Siblings & $110 / 918(12.0)$ & $51 / 460(11.1)$ & $59 / 458(12.9)$ & 0.402 \\
\hline Grandparents & $91 / 908(10.0)$ & $40 / 458(8.7)$ & $51 / 450(11.3)$ & 0.192 \\
\hline
\end{tabular}


Table 3. Forms of childhood maltreatment $(N=1201)$

\begin{tabular}{|c|c|c|c|c|c|}
\hline Items & $\begin{array}{l}\text { Total } \\
n(\%)\end{array}$ & $\begin{array}{l}\text { Male } \\
n(\%)\end{array}$ & $\begin{array}{l}\text { Female } \\
n(\%)\end{array}$ & $\boldsymbol{P}$ & $\begin{array}{l}\text { Can't } \\
\text { remember } \\
n(\%)\end{array}$ \\
\hline \multicolumn{6}{|l|}{ Physical maltreatment } \\
\hline Hit or punched & $808(67.3)$ & $411(70.6)$ & $397(64.1)$ & 0.056 & $31(2.6)$ \\
\hline Kicked & $336(28.0)$ & $208(35.7)$ & $128(20.7)$ & $<0.001$ & $137(11.4)$ \\
\hline Hit with implements & $448(37.3)$ & $246(42.3)$ & $202(32.6)$ & 0.002 & $48(4.0)$ \\
\hline Shaken hard & 201(16.7) & $121(20.8)$ & $80(12.0)$ & 0.001 & 199(16.6) \\
\hline Stabbed/cut with a knife/sharp object & $25(2.1)$ & $15(2.6)$ & $10(1.6)$ & 0.129 & $16(1.3)$ \\
\hline $\begin{array}{l}\text { Burned or scalded(e.g., cigarettes) or punctured (e.g., } \\
\text { needles) }\end{array}$ & $16(1.3)$ & $8(1.4)$ & $8(1.4)$ & 0.361 & $15(1.2)$ \\
\hline Forced to stand $/$ kneel in a humiliating or painful way & $616(51.3)$ & $351(60.5)$ & $265(42.8)$ & $<0.001$ & $31(2.6)$ \\
\hline \multicolumn{6}{|l|}{ Emotional maltreatment } \\
\hline Refused to talk to/ignored which made them feel hurt & $485(40.4)$ & $220(37.9)$ & $265(42.8)$ & 0.035 & 143(11.9) \\
\hline $\begin{array}{l}\text { Insulted or criticized that made them feel bad, stupid } \\
\text { or worthless }\end{array}$ & $596(49.6)$ & $265(46.3)$ & $327(52.8)$ & 0.076 & $74(6.2)$ \\
\hline Told they were not loved or did not deserve love & $72(6.0)$ & $37(6.4)$ & $35(5.7)$ & 0.690 & $53(4.4)$ \\
\hline Wished they were dead & $113(9.4)$ & $46(7.9)$ & $67(10.8)$ & 0.188 & $35(2.9)$ \\
\hline Threatened they would be badly hurt & 203(16.9) & $138(23.8)$ & $65(10.5)$ & $<0.001$ & 41(3.4) \\
\hline Threatened to spank without actually doing it & $647(53.9)$ & $349(60.1)$ & $298(48.1)$ & $<0.001$ & $75(6.2)$ \\
\hline Threatened with abandonment & $174(14.5)$ & $84(14.5)$ & $90(14.5)$ & 0.194 & $43(3.6)$ \\
\hline
\end{tabular}


Table 4. Risk Factors of Physical and Emotional Maltreatment by Perpetrator: Logistic Regression (to be continued)

\begin{tabular}{|c|c|c|c|c|c|c|c|c|}
\hline \multirow[t]{2}{*}{ Risk factors } & \multicolumn{2}{|c|}{$\begin{array}{l}\text { PM by any perpetrator } \\
\qquad(\mathrm{N}=1163)\end{array}$} & \multicolumn{2}{|c|}{$\begin{array}{c}\text { EM by any perpetrator } \\
(\mathrm{N}=1141)\end{array}$} & \multicolumn{2}{|c|}{$\begin{array}{l}\text { PM by parents } \\
\qquad(\mathrm{N}=1105)\end{array}$} & \multicolumn{2}{|c|}{$\begin{array}{l}\text { EM by parents } \\
\qquad(\mathrm{N}=1042)\end{array}$} \\
\hline & OR(95\% CI) & $\boldsymbol{P}$ & OR(95\% CI) & $P$ & OR(95\% CI) & $P$ & OR(95\% CI) & $\boldsymbol{P}$ \\
\hline Age & $1.19(1.04,1.36)$ & 0.009 & $1.19(1.03,1.37)$ & 0.018 & $1.10(0.99,1.22)$ & 0.082 & $1.08(0.98,1.20)$ & 0.119 \\
\hline \multicolumn{9}{|l|}{ Gender (ref.=Female) } \\
\hline Male & $1.83(1.32,2.55)$ & $<0.001$ & $0.94(0.67,1.33)$ & 0.728 & $1.33(1.02,1.73)$ & 0.037 & $0.71(0.54,0.91)$ & 0.008 \\
\hline \multicolumn{9}{|c|}{ Single child (ref.=No) } \\
\hline Yes & $0.69(0.48,0.99)$ & 0.043 & $0.90(0.62,1.31)$ & 0.597 & $0.91(0.68,1.22)$ & 0.523 & $0.93(0.70,1.23)$ & 0.607 \\
\hline \multicolumn{9}{|c|}{ Rural Residence (ref.=Urban) } \\
\hline Rural & $0.92(0.62,1.37)$ & 0.690 & $0.77(0.51,1.17)$ & 0.221 & $0.75(0.55,1.03)$ & 0.078 & $0.63(0.47,0.86)$ & 0.004 \\
\hline \multicolumn{9}{|c|}{ Marital status (ref.=Married) } \\
\hline Separated/Divorced & $0.89(0.38,2.11)$ & 0.796 & $1.55(0.51,4.71)$ & 0.438 & $0.97(0.47,1.98)$ & 0.928 & $1.05(0.53,2.07)$ & 0.890 \\
\hline Widowed & $2.92(0.37,23.01)$ & 0.309 & $0.63(0.17,2.35)$ & 0.487 & $1.27(0.39,4.09)$ & 0.688 & $0.60(0.24,1.53)$ & 0.285 \\
\hline Remarried & $3.01(0.38,23.56)$ & 0.294 & $2.61(0.33,20.41)$ & 0.361 & $1.44(0.46,4.58)$ & 0.532 & $5.12(1.11,23.59)$ & 0.036 \\
\hline \multicolumn{9}{|c|}{ Father's education (ref.=Primary school or below) } \\
\hline $\begin{array}{l}\text { Junior middle } \\
\text { school }\end{array}$ & $1.28(0.83,2.00)$ & 0.268 & $0.91(0.57,1.45)$ & 0.691 & $1.18(0.82,1.69)$ & 0.374 & $1.02(0.72,1.44)$ & 0.917 \\
\hline High school & $0.96(0.59,1.58)$ & 0.882 & $0.90(0.53,1.53)$ & 0.693 & $0.85(0.56,1.28)$ & 0.432 & $0.94(0.63,1.40)$ & 0.774 \\
\hline University or above & $1.47(0.73,2.96)$ & 0.283 & $1.28(0.60,2.76)$ & 0.524 & $1.21(0.68,2.15)$ & 0.516 & $1.28(0.74,2.23)$ & 0.379 \\
\hline \multicolumn{9}{|c|}{ Mother's education (ref.=Primary school or below) } \\
\hline $\begin{array}{l}\text { Junior middle } \\
\text { school }\end{array}$ & $0.95(0.64,1.43)$ & 0.820 & $0.95(0.63,1.45)$ & 0.820 & $1.04(0.75,1.45)$ & 0.808 & $0.91(0.67,1.25)$ & 0.566 \\
\hline High school & $1.07(0.61,1.87)$ & 0.820 & $0.84(0.47,1.49)$ & 0.549 & $0.82(0.53,1.28)$ & 0.378 & $0.78(0.51,1.20)$ & 0.265 \\
\hline University or above & $0.59(0.29,1.20)$ & 0.146 & $1.06(0.46,2.44)$ & 0.894 & $0.68(0.37,1.23)$ & 0.202 & $0.83(0.45,1.52)$ & 0.541 \\
\hline \multicolumn{9}{|c|}{ Economic status(ref.=High-income) } \\
\hline Middle & $1.16(0.73,1.84)$ & 0.534 & $1.07(0.65,1.78)$ & 0.782 & $1.24(0.85,1.82)$ & 0.263 & $1.15(0.79,1.70)$ & 0.465 \\
\hline Low-income & $1.22(0.67,2.22)$ & 0.508 & $1.55(0.80,2.98)$ & 0.193 & $1.39(0.86,2.26)$ & 0.177 & $1.35(0.84,2.18)$ & 0.215 \\
\hline \multicolumn{9}{|c|}{ Residence status (ref.=neither) } \\
\hline Either & $0.72(0.23,2.22)$ & 0.568 & $0.68(0.21,2.24)$ & 0.524 & $1.36(0.59,3.16)$ & 0.473 & $0.93(0.44,1.96)$ & 0.855 \\
\hline Both & $0.55(0.26,1.19)$ & 0.130 & $0.48(0.21,1.08)$ & 0.075 & $0.89(0.53,1.50)$ & 0.661 & $1.01(0.62,1.64)$ & 0.981 \\
\hline
\end{tabular}

PM: physical maltreatment; EM: emotional maltreatment 
Table 4. Risk Factors of Physical and Emotional Maltreatment by Perpetrator: Logistic Regression (continued)

\begin{tabular}{|c|c|c|c|c|c|c|c|c|c|c|c|c|c|c|c|c|}
\hline \multirow{2}{*}{ Risk factors } & \multicolumn{2}{|c|}{ PM by teachers } & \multicolumn{2}{|c|}{ EM by teachers } & \multicolumn{2}{|c|}{ PM by peer } & \multicolumn{2}{|c|}{ EM by peer } & \multicolumn{2}{|c|}{ PM by siblings } & \multicolumn{2}{|c|}{ EM by siblings } & \multicolumn{2}{|c|}{ PM by grandparents } & \multicolumn{2}{|c|}{ EM by grandparents } \\
\hline & OR(95\% CI) & $P$ & OR( $(95 \%$ CI) & $P$ & OR(95\% CI) & $P$ & OR(95\% CI) & $P$ & OR(95\% CI) & $P$ & OR $(95 \% \mathrm{CI})$ & $P$ & OR(95\% CI) & $P$ & OR $(95 \% \mathrm{CI})$ & $P$ \\
\hline Age & $1.18(1.07,1.31)$ & 0.001 & $1.11(1.00,1.23)$ & 0.047 & $1.03(0.91,1.16)$ & 0.647 & $0.96(0.87,1.06)$ & 0.440 & $1.11(0.93,1.32)$ & 0.231 & $1.01(0.85,1.19)$ & 0.918 & $1.07(0.88,1.30)$ & 0.511 & $1.03(0.86,1.24)$ & 0.710 \\
\hline Single child $(\mathrm{ref}=\mathrm{No}$ ) & $0.76(0.57,1.01)$ & 0.055 & $1.10(0.83,1.47)$ & 0.501 & $0.67(0.48,0.92)$ & 0.014 & $1.01(0.76,1.33)$ & 0.961 & $0.21(0.12,0.36)$ & $<0.001$ & $0.30(0.18,0.51)$ & $<0.001$ & $0.98(0.57,1.68)$ & 0.945 & $1.50(0.88,2.54)$ & 0.133 \\
\hline $\begin{array}{l}\text { Rural Residence } \\
\text { (ref.=Urban) }\end{array}$ & $1.11(0.81,1.51)$ & 0.513 & $0.77(0.56,1.05)$ & 0.094 & $1.19(0.83,1.70)$ & 0.340 & $0.96(0.71,1.30)$ & 0.782 & $0.82(0.49,1.37)$ & 0.453 & $0.80(0.48,1.33)$ & 0.387 & $1.32(0.72,2.41)$ & 0.370 & $1.30(0.73,2.33)$ & 0.379 \\
\hline \multicolumn{17}{|l|}{ Marriage(ref.=Married) } \\
\hline Separated/Divorced & $0.80(0.40,1.60)$ & 0.521 & $0.65(0.31,1.37)$ & 0.256 & $1.34(0.62,2.91)$ & 0.462 & $1.67(0.81,3.44)$ & 0.163 & $0.98(0.30,3.20)$ & 0.979 & $0.50(0.11,2.31)$ & 0.373 & $1.25(0.40,3.88)$ & 0.703 & $0.67(0.22,2.09)$ & 0.495 \\
\hline Widowed & $0.78(0.27,2.20)$ & 0.636 & $0.81(0.31,2.11)$ & 0.668 & $2.04(0.73,5.70)$ & 0.175 & $0.54(0.20,1.47)$ & 0.228 & $2.34(0.73,7.54)$ & 0.155 & $1.89(0.65,5.50)$ & 0.246 & $0.38(0.04,3.30)$ & 0.377 & $0.19(0.02,1.62)$ & 0.129 \\
\hline Remarried & $2.51(0.66,9.50)$ & 0.176 & $1.75(0.59,5.13)$ & 0.311 & $0.87(0.22,3.53)$ & 0.850 & $1.43(0.49,4.15)$ & 0.510 & $1.46(0.28,7.67)$ & 0.656 & $1.15(0.23,5.68)$ & 0.860 & $4.19(1.21,14.56)$ & 0.024 & $0.61(0.07,5.10)$ & 0.645 \\
\hline \multicolumn{17}{|c|}{ Father's education (ref.=Primary school or below) } \\
\hline Junior middle school & $1.00(0.70,1.42)$ & 0.997 & $1.02(0.72,1.46)$ & 0.902 & $0.56(0.38,0.83)$ & 0.003 & $0.93(0.65,1.31)$ & 0.666 & $0.77(0.44,1.33)$ & 0.344 & $0.91(0.53,1.56)$ & 0.724 & $1.27(0.64,2.52)$ & 0.498 & $1.00(0.51,1.96)$ & 1.000 \\
\hline High school & $1.03(0.68,1.55)$ & 0.886 & $1.07(0.72,1.61)$ & 0.736 & $0.60(0.38,0.94)$ & 0.026 & $0.69(0.46,1.02)$ & 0.064 & $0.82(0.43,1.58)$ & 0.556 & $0.89(0.47,1.68)$ & 0.728 & $1.07(0.48,2.37)$ & 0.872 & $1.47(0.72,2.99)$ & 0.287 \\
\hline \multicolumn{17}{|c|}{ Mother's education (ref.=Primary school or below) } \\
\hline Junior middle school & $0.95(0.69,1.30)$ & 0.749 & $0.94(0.68,1.29)$ & 0.688 & $1.17(0.82,1.67)$ & 0.379 & $0.90(0.66,1.23)$ & 0.513 & $0.94(0.56,1.57)$ & 0.799 & $0.70(0.43,1.15)$ & 0.160 & $0.48(0.25,0.91)$ & 0.024 & $1.06(0.59,1.89)$ & 0.855 \\
\hline High school & $1.14(0.74,1.77)$ & 0.550 & $0.68(0.44,1.06)$ & 0.087 & $1.14(0.69,1.89)$ & 0.610 & $1.12(0.72,1.74)$ & 0.611 & $1.26(0.61,2.62)$ & 0.534 & $0.94(0.46,1.91)$ & 0.864 & $1.22(0.57,2.63)$ & 0.613 & $0.79(0.34,1.84)$ & 0.587 \\
\hline University or above & $1.24(0.68,2.26)$ & 0.478 & $0.75(0.41,1.39)$ & 0.360 & $1.16(0.57,2.35)$ & 0.690 & $1.37(0.75,2.51)$ & 0.311 & $1.32(0.41,4.33)$ & 0.641 & $0.71(0.23,2.15)$ & 0.546 & $0.72(0.24,2.14)$ & 0.551 & $2.02(0.73,5.61)$ & 0.175 \\
\hline \multicolumn{17}{|c|}{ Economic status (ref.=High-income) } \\
\hline Middle & $1.25(0.85,1.84)$ & 0.253 & $0.92(0.62,1.35)$ & 0.667 & $1.21(0.76,1.92)$ & 0.431 & $0.70(0.48,1.03)$ & 0.069 & $2.24(0.91,5.49)$ & 0.079 & $0.96(0.48,1.90)$ & 0.902 & $0.73(0.37,1.44)$ & 0.370 & $1.17(0.58,2.36)$ & 0.660 \\
\hline Low-income & $1.36(0.84,2.19)$ & 0.205 & $1.11(0.69,1.79)$ & 0.674 & $1.39(0.80,2.41)$ & 0.245 & $1.29(0.80,2.08)$ & 0.293 & $3.11(1.19,8.16)$ & 0.021 & $1.67(0.78,3.58)$ & 0.191 & $0.92(0.40,2.12)$ & 0.846 & $3.00(1.32,6.79)$ & 0.008 \\
\hline \multicolumn{17}{|c|}{ Residence status (ref.=neither) } \\
\hline Either & $0.75(0.33,1.68)$ & 0.484 & $0.75(0.35,1.59)$ & 0.448 & $0.66(0.27,1.65)$ & 0.375 & $0.86(0.40,1.85)$ & 0.697 & $1.40(0.46,4.32)$ & 0.553 & $0.90(0.30,2.70)$ & 0.856 & $0.40(0.13,1.24)$ & 0.112 & $0.73(0.25,2.13)$ & 0.570 \\
\hline Both & $0.54(0.32,0.92)$ & 0.024 & $0.57(0.35,0.92)$ & 0.023 & $1.07(0.61,1.87)$ & 0.807 & $0.69(0.41,1.13)$ & 0.142 & $1.05(0.48,2.31)$ & 0.894 & $0.77(0.38,1.55)$ & 0.464 & $0.23(0.12,0.45)$ & $<0.001$ & $0.25(0.12,0.50)$ & $<0.001$ \\
\hline
\end{tabular}

PM: physical maltreatment; EM: emotional maltreatment 
Table 5. Perceptions of Harm of Physical and Emotional Maltreatment

\begin{tabular}{lccc}
\hline Types of child maltreatment & Not at all & Mild & $\begin{array}{c}\text { Severe/very } \\
\text { severe }\end{array}$ \\
\hline Physical maltreatment & & & \\
Hit or punched & $351(43.7)$ & $375(46.6)$ & $78(9.7)$ \\
Kicked & $132(39.5)$ & $152(45.5)$ & $50(15.0)$ \\
Hit with implements & $158(35.5)$ & $225(50.6)$ & $62(13.9)$ \\
Shook hard & $123(61.2)$ & $62(30.8)$ & $16(8.0)$ \\
Stabbed or cut with a knife or sharp object & $7(28.0)$ & $13(52.0)$ & $5(20.0)$ \\
Burned or scalded(e.g., cigarettes) or punctured (e.g., & $2(13.3)$ & $8(53.3)$ & $5(33.3)$ \\
needles) & $246(40.1)$ & $295(48.0)$ & $73(11.9)$ \\
Forced to stand/kneel & & & \\
Emotional maltreatment & $70(14.5)$ & $306(63.4)$ & $107(22.2)$ \\
Refused to talk/ignored that made them feel hurt & $69(11.7)$ & $341(59.5)$ & $170(28.8)$ \\
Insulted or criticized that made them feel bad, stupid or & $15(20.8)$ & $25(34.7)$ & $32(44.4)$ \\
worthless & $23(20.7)$ & $44(39.6)$ & $44(39.6)$ \\
Told they were not loved or did not deserve love & $55(27.9)$ & $105(53.3)$ & $37(18.8)$ \\
Wished they were dead & $350(56.7)$ & $228(37.0)$ & $39(6.3)$ \\
Threatened they would be badly hurt or killed & $56(32.9)$ & $73(42.9)$ & $41(24.1)$ \\
Threatened to spank without actually doing it & & & \\
Threatened with abandonment &
\end{tabular}




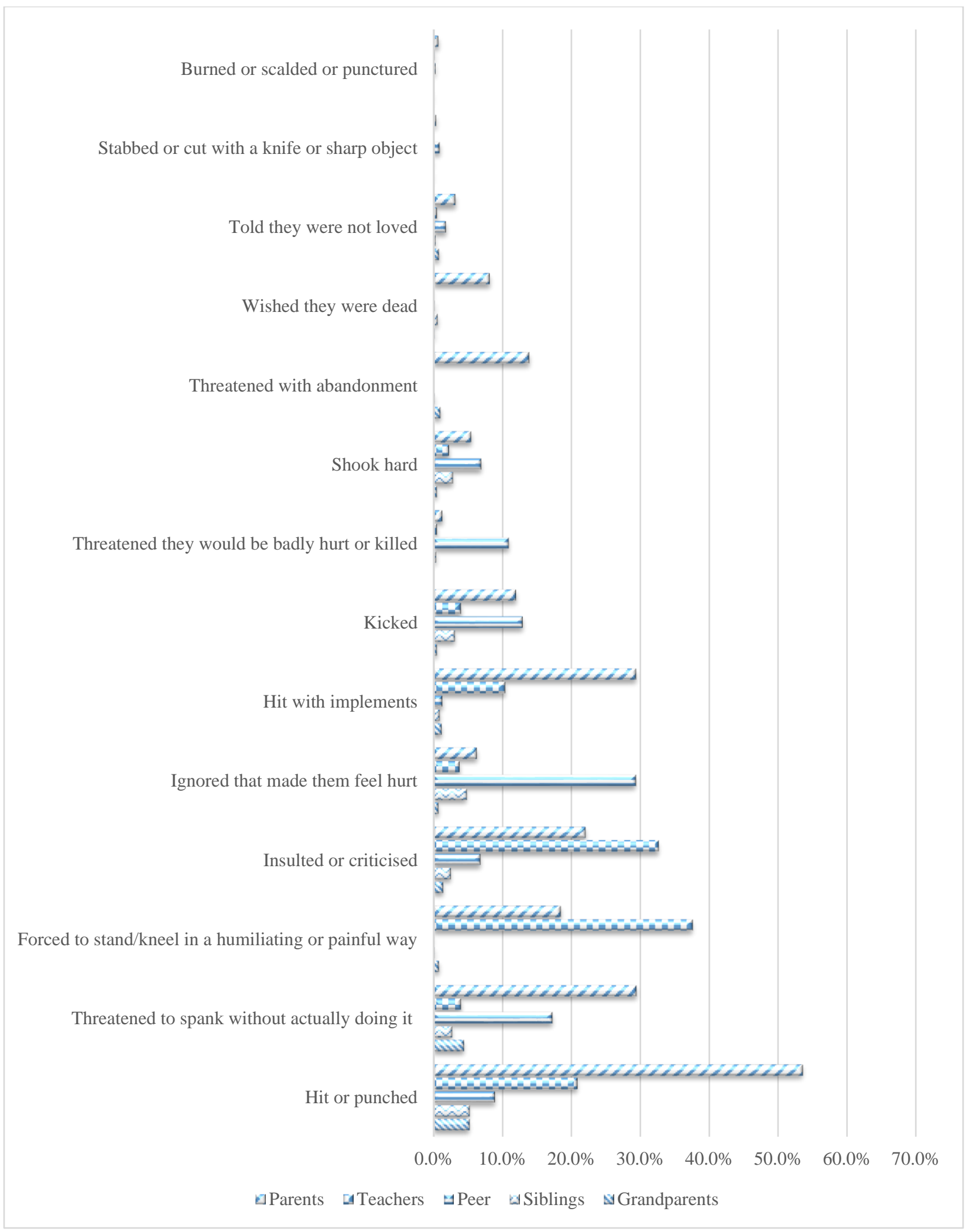

Figure 1. Common Forms of Violence Against Children by Type of Perpetrator 